\title{
Atypical Wegener's Granulomatosis with Positive Cytoplasmic Antineutrophil Cytoplasmic Antibodies, Ophthalmologic Manifestations, and Slowly Progressive Renal Failure without Respiratory Tract Involvement
}

\author{
Tomoko Kakizawa, Kazuo Ichikawa, Keishi Yamauchi, Teiji Takeda, Minoru Nagai, Jun-ichiro Mori, \\ Wataru Yumita, Takahide Miyamoto, Takeshi Nagasawa and Kiyoshi Hashizume
}

\begin{abstract}
A 68-year-old woman had microscopic hematuria and proteinuria since the age of 50 . She also had hearing impairment, arthralgia, retinal embolism, peripheral arterial occlusion of the right foot and chronic renal failure during the course. At the age of 68, she had progressive renal failure and nephrotic syndrome with high titers of serum cytoplasmic antineutrophil cytoplasmic antibodies (c-ANCA). No evidence of respiratory tract involvement was found. Methylprednisolone pulse therapy and low dose cyclophosphamide therapy ameliorated the renal failure and reduced the serum c-ANCA level. She, however, died on July 19, 1998 due to pulmonary fungal and pneumocystis carinii infection.
\end{abstract}

(Internal Medicine 38: 679-682, 1999)

Key words: nephrotic syndrome, retinal embolism, immunosuppressive therapy

\section{Introduction}

Antineutrophil cytoplasmic antibodies (ANCA) (1) are directed against certain proteins in the cytoplasm of neutrophils. They are present in the serum of patients with Wegener's granulomatosis, necrotizing crescentic glomerulonephritis, polyarteritis nodosa, microscopic polyangitis, allergic angitis and granulomatosis (Churg-Strauss disease), vasculitis associated with the other collagen vascular diseases, and sometimes in inflammatory bowel diseases (2-4). Two major categories of ANCA are present based upon different immunofluorescence-staining patterns. Cytoplasmic (c) ANCA refers to the diffuse, granular cytoplasmic staining pattern and the major target antigen is proteinase-3 (5). Perinuclear (p) ANCA refers to the more localized perinuclear or nuclear staining pattern and major target antigens are the enzyme myeloperoxidase (6) and infrequently, elastase. c-ANCA is highly specific for Wegener's granulomatosis $(7,8)$, whereas other disorders are associated with positive p-ANCA except for microscopic polyangitis which can show positive c-ANCA (6). The role of ANCA in the pathogenesis of this vasculitis is unknown $(2,9)$. The prognosis of ANCA positive glomerulonephritis, however, is poor, once progressive renal failure ensues $(2,10,11)$.
For editorial comment, see also p 619.

Here, we report an elderly case of c-ANCA positive vasculitis and progressive renal failure that was treated with methylprednisolone pulse therapy followed by conventional glucocorticoid and low-dose cyclophosphamide therapy.

\section{Case Report}

A 68-year-old woman was hospitalized on February 3, 1998 because of progressive renal failure. In 1980, microscopic hematuria was noticed. when she was admitted to another hospital due to bronchitis. In 1982, haematuria and proteinuria was pointed out as she was hospitalized due to Herpes Zoster. Since 1984, she suffered from hypertension and received medical treatment. In 1992 she had tinnitus, vertigo, and difficulty in hearing in the right ear and was hospitalized for medical management. Hearing impairment in the right ear, however, did not improve. In 1992, she also had arthralgia which was diagnosed as rheumatoid arthritis and she received $5 \mathrm{mg} /$ day of prednisolone. On August 15, 1992, her left visual acuity got worse suddenly which was due to left retinal embolism. Two

From the Department of Geriatrics, Shinshu University School of Medicine, Matsumoto

Received for publication November 30, 1998; Accepted for publication April, 1999

Reprint requests should be addressed to Dr. Kazuo Ichikawa, the Department of Geriatrics, Shinshu University School of Medicine, Asahi 3-1-1, Matsumoto, Nagano 390-8621 
days later, she had severe pain in the right toe with cyanosis (the first to third toes on the right foot). She was transferred to the department of surgery of our hospital for peripheral arterial occlusion of the right foot which was successfully treated with anti-thrombotic therapy and administration of prostaglan$\operatorname{din} E_{1}$. She was referred to our department because of hematuria and proteinuria. Her serum creatinine level was $1.6 \mathrm{mg} / \mathrm{dl}$ with a creatinine clearance of $20 \mathrm{ml} / \mathrm{min}$. She continued to take $5 \mathrm{mg}$ of prednisolone and started to take nifedipine and ticlopidine hydrochloride for possible angitis. Proteinuria decreased from $1.5 \mathrm{~g} /$ day to $0.5 \mathrm{~g} /$ day. Renal biopsy was not performed. Prednisolone was discontinued in July 1993 at the outpatient clinic without recurrence. She had been stable until August 1997 when she had pain in her right toe which subsided after intravenous administration of prostaglandin $\mathrm{E}_{1}$. In October 1997, her serum creatinine level increased to $2.5 \mathrm{mg} /$ $\mathrm{dl}$ which further increased to $3.3 \mathrm{mg} / \mathrm{dl}$ in January 1998. She became nephrotic with urinary protein excretion of $4.5 \mathrm{~g}$ per day, serum total protein level $4.9 \mathrm{~g} / \mathrm{dl}$, albumin $2.8 \mathrm{~g} / \mathrm{dl}$, total cholesterol $357 \mathrm{mg} / \mathrm{dl}$ and overt pitting edema of legs. Serum c-ANCA, examined by enzyme-linked immunosorbent assay (ELISA) using proteinase 3 as the antigen, was strongly positive (above 1,000 EU). She was admitted to our department for the treatment of renal failure and nephrotic syndrome. On admission, she was an anemic woman, $155.3 \mathrm{~cm}$ tall and body weight, $48.4 \mathrm{~kg}$. Her blood pressure was $126 / 72 \mathrm{mmHg}$, and pulse rate was $60 / \mathrm{min}$ with regular rhythm. She had a slightly enlarged diffuse goiter and pitting edema in both legs. Chest and abdominal examination revealed no abnormalities. There was no evidence of arthritis on physical examination and on $\mathrm{X}$-ray examination of articular bone. Laboratory data revealed an erythrocyte sedimentation rate of $77 \mathrm{~mm} / \mathrm{h}$, hemoglobin level $7.4 \mathrm{~g} / \mathrm{dl}$, red blood cell count $240 \times 10^{4}$ per cubic $\mathrm{mm}$, hematocrit $24.1 \%$, and white blood cell (WBC) count 4950 per cubic mm (Segmental neutrocyte 53\%, Band 5\%, Monocyte 9\%, Eosinophil 5\%, Basophil 0\%, Lymphocyte 28\%). Plasma C reactive protein level was $0.12 \mathrm{mg} / \mathrm{dl}$, plasma total protein 4.4 $\mathrm{g} / \mathrm{dl}$, albumin $2.5 \mathrm{~g} / \mathrm{dl}$, blood urea nitrogen (BUN) $66 \mathrm{mg} / \mathrm{dl}$, creatinine $3.1 \mathrm{mg} / \mathrm{dl}, \mathrm{Na} 142 \mathrm{mEq} / l, \mathrm{~K} 4.3 \mathrm{mEq} / l, \mathrm{Cl} 114$ $\mathrm{mEq} / l$, Ca $8.0 \mathrm{mg} / \mathrm{dl}, \mathrm{P} 4.9 \mathrm{mg} / \mathrm{dl}$, amylase $203 \mathrm{U} / \mathrm{l}$ and total cholesterol $252 \mathrm{mg} / \mathrm{dl}$. Her hepatic function was normal. Serum levels of immunoglobulin (Ig) G, IgA, and IgM were 373 , 108 , and $45 \mathrm{mg} / \mathrm{dl}$, respectively. p-ANCA and anti-glomerular basement membrane antibody were negative. Anti-nuclear antibody, rheumatoid factor, anti-cardiolipin antibody, anti-thyroid microsomal antibody, and anti-thyroglobulin antibody were negative. Urinalysis revealed that urinary protein was $3+$, occult blood $3+$ and sediment contained 30 red blood cells, 3 white blood cells, hyaline and WBC casts and no bacteria per high power field. She excreted urinary protein of $4.1 \mathrm{~g} /$ day and urinary albumin of $3.6 \mathrm{~g} /$ day. Creatinine clearance was $13 \mathrm{ml} /$ min. Serum complement levels were normal. In the renal biopsy specimen, only two glomeruli were observed. One glomerulus was collapsed and the other one showed proliferation of mesangial cells and partial membranous change without crescent formation (Fig. 1). Immunofluorescent study revealed

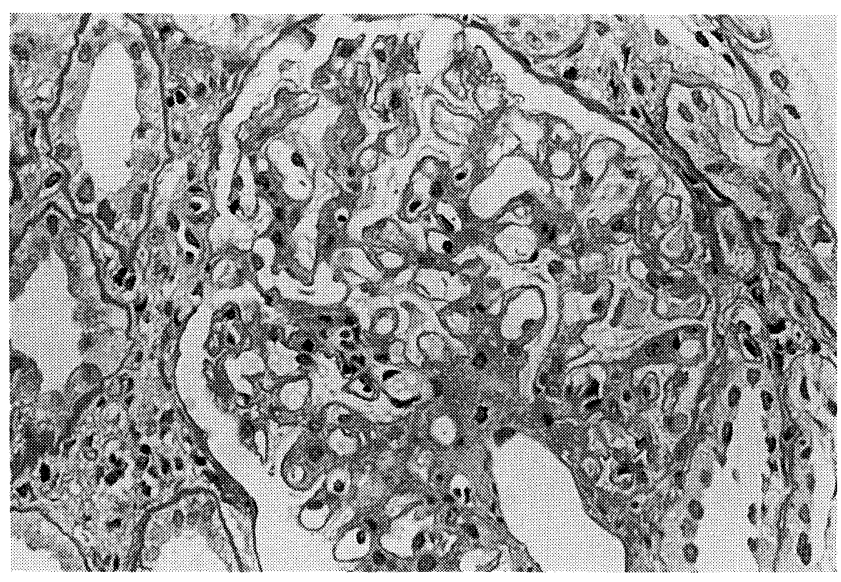

Figure 1. Light microscopic examination of renal biopsy tissue. Hematoxylin and eosin staining of one of two glomeruli obtained from a renal biopsy shows proliferation of mesangial cells and partial membranous change (HE stain, $\times 560$ ).

negative immunoglobulin accumulation in the renal biopsy specimen. Chest roentgenogram revealed no abnormality. However, chest computed tomography (CT) scan revealed dormant atypical micobacterial infection. No evidence of Wegener's granuloma was found in chest CT scan, magnetic resonance imaging (MRI), or in a nasopharyngeal examination performed by an otolaryngologist. Her disorder was diagnosed as c-ANCA positive vasculitis. Intravenous administration of methylprednisolone (1,000 mg/day) was started on February 26 and was continued for 3 days; this was followed by oral administration of prednisolone $(60 \mathrm{mg} /$ day $)$. Cyclophosphamide $(50 \mathrm{mg} / \mathrm{day}$ per os) and continuous intravenous infusion of heparin $(10,000$ units/day) were started at the same time. The serum creatinine level and titers of c-ANCA were decreased gradually over a few months (Fig. 2). Urinary protein excretion was also decreased. On March 13, perforation of the right femoral artery occurred with massive hematoma in the right thigh and retroperitoneum. Hypovolemic shock ensued and was relieved by blood transfusion. On March 23, cyclophosphamide was discontinued because of granulocytopenia with no evidence of infection. On May 11, a slight abnormal shadow appeared in the peripheral portion of the right middle lung field on chest roentgenogram when she was taking $30 \mathrm{mg}$ prednisolone per day. The shadow was spread over both lungs on May 15. Diagnosis of pulmonary fungal and pneumocystis carinii infection was made upon chest CT scan, bronchoscopy with lung biopsy and polymerase chain reaction (PCR) analysis of bronchoalveolar larvage and serological examinations. She received fluconazole and trimethoprim/sulfamethoxazole. She also received methylprednisolone pulse therapy for the ARDS. Tracheal intubation and mechanical ventilation were required due to respiratory failure. She also received continuous hemodialysis for the progressive renal failure. She died of respiratory failure on July 19, 1998. 


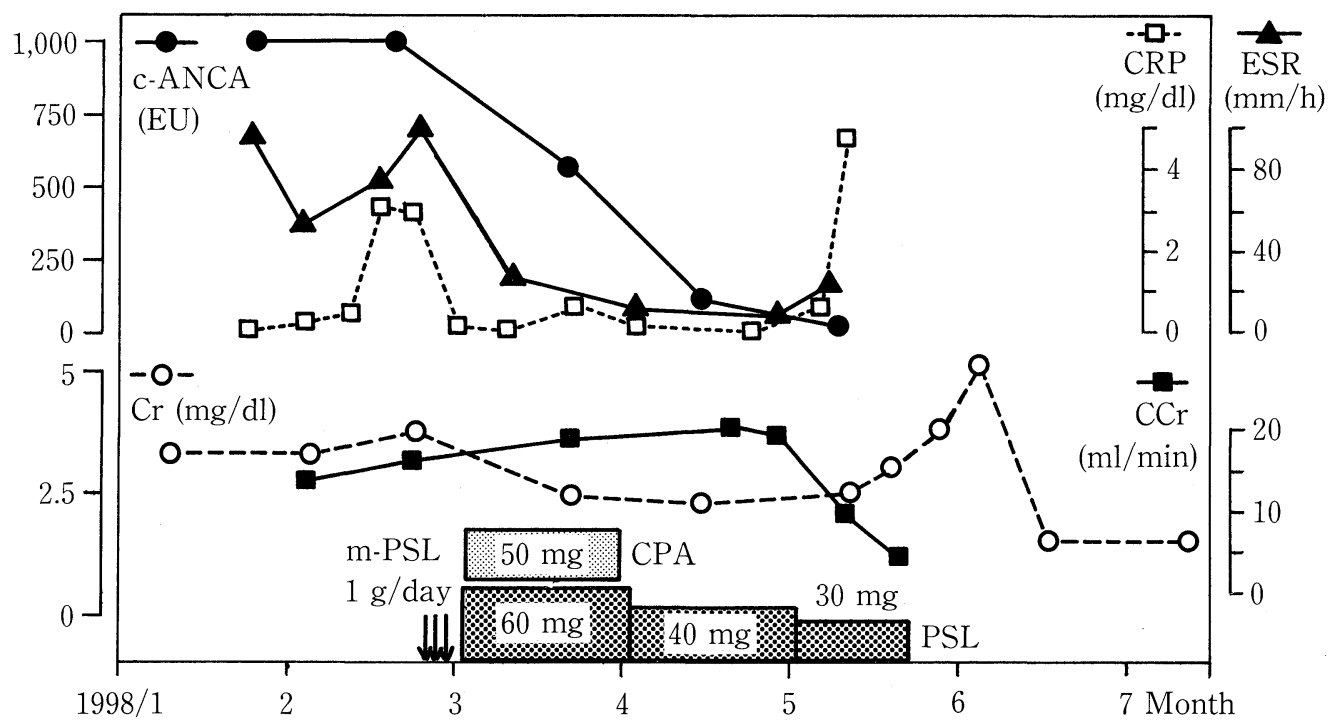

Figure 2. Clinical course and response to therapy. CCr: creatinine clearance, $\mathrm{Cr}$ : creatinine, CPA: cyclophosphamide, CRP: c-reactive protein, ESR: erythrocyte sedimentation rate, PSL: prednisolone.

\section{Discussion}

A case of vasculitis and renal failure with positive c-ANCA was demonstrated. Although c-ANCA is highly specific to Wegener's granulomatosis $(7,8)$, the present case lacked the granulomatous vasculitis of the upper and lower respiratory tract. Several cases of atypical Wegener's granulomatosis have also been reported, in whom only the positive tests for c-ANCA in serum were used to make the diagnosis and led to appropriate treatment (12). The clinically evident manifestation of vasculitis in the present case involved otological problems (difficulty in hearing, tinnitus, and vertigo), polyarthralgia, retinal embolism and ischemic foot disorders that started in 1992 and recurrent ischemic foot disorder, progressive renal failure and nephrotic syndrome that occured in 1997. These problems are frequently present in ANCA positive vasculitis. Although our patient suffered from hematuria and proteinuria since 1980 and from chronic renal failure since 1992, it is not certain whether this chronic glomerular nephritis is part of the ANCA positive vasculitis or not, because these findings are not specific to ANCA positive vasculitis and there was no histological evidence. We, however, consider that renal failure, proteinuria, and hematuria that progressed after 1992 was due to c-ANCA positive vasculitis as the progression was associated with onset and aggravations of systemic vasculitis, although proteinuria rarely develops into nephrotic syndrome in Wegener's granulomatosis. It is possible that the massive bleeding in the right thigh was due to the arterial involvement of vasculitis. It was unfortunate that the renal biopsy specimen contained only two glomeruli and no active lesions were detected. From these manifestations, our clinical diagnosis of the patient was atypical Wegener's granulomatosis lacking respiratory tract involvement, as c-ANCA is highly specific to this disorder. To prevent further exacerbation of renal failure and vasculitis, we gave methylprednisolone pulse therapy followed by conventional glucocorticoid and low-dose cyclophosphamide therapy. The treatment was successful in terms of prevention of renal failure, subsidence of c-ANCA titer and vasculitis. Unfortunately, however, the patient died of pneumocystis carinii and fungal pneumonia which is the result of immunosuppression created by the large dose of glucocorticoid therapy.

The prognosis of progressive renal failure in patients with positive c-ANCA used to be poor $(2,10,11)$. The recent introduction of large dose-glucocorticoid and cyclophosphamide treatment has improved its prognosis (13). It should be noted, however, that certain types of morbidity and mortality are related to the side effects of treatment (2). In the present case, the patient responded well to the therapeutic regimen described above, but the mortality was associated with the immunosuppressive side effect of the treatment which is important to note, especially when treating older patients.

\section{References}

1) Davies DJ, Moran JE, Niall JF, Ryan GB. Segmental necrotising glomerulonephritis with anti-neutrophil antibody: possible arbovirus aetiology? Br Med J (Clin Res Ed) 285: 606, 1982.

2) Hoffman GS, Kerr GS, Leavitt RY, et al. Wegener granulomatosis: an analysis of 158 patients. Ann Intern Med 116: 488-498, 1992 (see comments).

3) Nolle B, Specks U, Ludemann J, Rohrbach MS, DeRemee RA, Gross WL. Anticytoplasmic autoantibodies: Their immunodiagnostic value in Wegener granulomatosis. Ann Intern Med 111: 28-40, 1989.

4) Savage COS, Winearls CG, Jones S, Marshall PD, Lockwood CM. Prospective study of radioimmunoassay for antibodies against neutrophil cytoplasm in diagnosis of systemic vasculitis. Lancet i: 1389-1393, 1987.

5) Ludemann J, Utecht B, Gross WL. Anti-neutrophil cytoplasm antibodies in Wegener's granulomatosis recognize an elastinolytic enzyme. J Exp Med 171: 357-362, 1990. 


\section{c-ANCA Positive Vasculitis}

6) Franssen C, Gras R, Kallenberg C, Hageluken C, Hoorntje S. Disease spectrum of patients with antineutrophil cytoplasmic autoantibodies of defined specificity: distinct differences between patients with anti-proteinase 3 and anti-myeloperoxidase autoantibodies. J Intern Med 244: 209-216, 1998.

7) Gross WL, Csernok E, Helmchen U. Antineutrophil cytoplasmic autoantibodies, autoantigens, and systemic vasculitis. APMIS 103: 81-97, 1995.

8) Rao JK, Allen NB, Feussner JR, Weinberger M. A prospective study of antineutrophil cytoplasmic antibody (c-ANCA) and clinical criteria in diagnosing Wegener's granulomatosis. Lancet 346: 926-931, 1995 (see comments) (published erratum appears in Lancet 346: 1308, 1995).

9) Mayet W-J, Csernok E, Szymkowiak C, Gross WL, Meyer zum
Buschenfelde KH. Human endothelial cells express proteinase 3, the target antigen of anticytoplasmic antibodies in Wegener's granulomatosis. Blood 82: 1221-1229, 1993.

10) Hollander D, Manning RT. The use of alkylating agents in the treatment of Wegener's granulomatosis. Ann Intern Med 67: 398-398, 1967.

11) Falk RJ, Jennette JC. ANCA small-vessel vasculitis. J Am Soc Nephrol 8: 314-322, 1997.

12) Rump JA, Laaff $\mathrm{H}$, Lang B, et al. ACPA reaction in atypical Wegener's disease. Diagnostic test. Dtsch Med Wochenschr 114: 2008-2013, 1989.

13) Fauci AS, Haynes BF, Kartz P, Wolff SM. Wegener's granulomatosis: Prospective clinical and therapeutic experience with 85 patients for 21 years. Ann Intern Med 98: 76-85, 1983. 